\title{
Reflexiones sobre Calímaco, Aitia fr. 1, vv. 21-32 y el programa poético helenístico
}

\author{
Discurso de apertura de las Primeras Jornadas de \\ Literatura Helenística del Instituto de Filología Clásica \\ de la Facultad de Filosofía y Letras de la Universidad de \\ Buenos Aires
}

Daniel Alejandro Torres

Para abrir este volume temático de Anales de Filología Clásica, que reúne trabajos originalmente presentados en las Primeras Jornadas de Literatura Helenística del Instituto de Filología Clásica -referato externo mediante-, retomaré las palabras del discurso de apertura, focalizándome en tres aspectos: en primer lugar, los antecedentes del evento en nuestros ámbitos académicos, su historial; en segundo lugar, la actualidad de las investigaciones sobre el período helenístico en el exterior y en nuestro país y, para cerrar la exposición, daré razón del logo que hemos elegido para las Jornadas con un breve comentario sobre su texto, los vv. 22-28 del fr. I de Aitia de Calímaco, que contienen las palabras de Apolo al joven poeta con el programa poético que habrá de ejercitar.

En el siglo pasado en nuestro país la literatura del período helenístico era un objeto de estudio más frecuentado por los latinistas que por los grecistas, que limitaban el estudio de la literatura griega a los períodos arcaico y clásico en sus prácticas docentes. En buena medida, esto reflejaba el estado de las investigaciones a nivel internacional, en el que el período helenístico todavía era visto como una etapa de decadencia de la cultura griega. Con la edición monumental de Pfeiffer de la obra de Calímaco, que dio lugar a numerosas ediciones comentadas de los Himnos individuales, y con la publicación de Ptolemaic Alexandria de Fraser fue aumentando el interés por los autores y obras del período, y en 1983 Lloyd-Jones y Parsons editan el Supplementum Hellenisticum, que reabre cuestionamientos anteriores, especialmente en relación con el ordenamiento de los fragmentos de Aitia, al tiempo que suministra un cuantioso corpus de nuevos textos antiguos. En ese marco internacional de investigación, el Dr. Rodolfo Buzón, anterior Director de este Instituto y el anterior Profesor Titular de Filología Griega, propuso la investigación sobre autores y obras del período helenístico y su influencia en la literatura latina como tema del IX Simposio Nacional de Estudios Clásicos, realizado en Buenos Aires en octubre de 1986. Ese Simposio fue el disparador original de la exploración del período helenístico en nuestros medios académicos, que se prosiguió con las VIII Jornadas Nacionales de Estudios Clásicos, realizadas en Rosario en mayo de 2001, Modalidad Taller, sobre la Carta VI de Epicuro, Jornadas en las que se propuso la Modalidad Taller sobre el Himno II de Calímaco para las siguientes Jornadas (IX Jornadas Nacionales de Estudios Clásicos), realizadas en Buenos Aires en mayo de 2003, en este Instituto. 
1. La tesis del Dr. Llanos fue defendida y aprobada con Sobresaliente y recomendación de publicación en la Facultad de Filosofía y Humanidades de la Universidad Nacional de Córdoba el día 23 de marzo de 2018. La tesis de la Dra. Rodoni fue defendida en el Departamento de Humanidades de la Universidad Nacional del Sur con calificación 10 (diez) Sobresaliente el día 25 de octubre de 2018.
En cuanto al ámbito internacional, la década de los '9o mostró un renovado interés por la literatura helenística con la realización de los Workshops Hellenistica Groningana, iniciados en 1993 sobre Calímaco y proseguidos sobre distintos autores, obras y temáticas hasta el volumen 23, en prensa. Un hito fundamental en este itinerario de la crítica fue el libro de Alan Cameron, Callimachus and his Critics (1995), porque sacó a Calímaco y a los poetas de su tiempo de la 'torre de marfil' a la que los había confinado la filología de los siglos XIX y XX y abrió el camino a la investigación sobre las relaciones entre la literatura conservada y su contexto social, político y religioso de producción. Un aporte clave de este libro fue instalar el tema de la performance como elemento de continuidad con la tradición poética arcaica y clásica, tema explorado por numerosos críticos en el siglo XXI (Stephens, 2003 y 2015, Vamvouri Ruffy, 2004; Prauscello, 2009, entre muchos otros, incluyendo los autores del presente volume temático) y el volumen 23 de Hellenistica Groningana lleva el sugestivo título de Drama and Performance in Hellenistic Poetry. En estas Jornadas se presentan dos trabajos sobre el concepto de 'ficción de performance original', una nueva herramienta crítica para el estudio de la literatura helenística en su conjunto. También contamos en el Instituto con la nueva edición comentada de los Aitia de Calímaco, a cargo de Annette Harder (2012), que incorpora los nuevos fragmentos del Supplementum Hellenisticum y presenta consecuentemente un nuevo ordenamiento de los fragmentos del poema, una edición hoy insoslayable, como la de Pfeiffer, a la espera de nuevos investigadores jóvenes que decidan orientar sus investigaciones doctorales al estudio del período helenístico. Ya tenemos en nuestro país dos tesis doctorales finalizadas: una en la Universidad Nacional del Sur, en Bahía Blanca, de la Lic. María Alejandra Rodoni, sobre el tema: "Perspectiva religiosa y renovación literaria en los Himnos de Calímaco"; la otra en la Universidad Nacional de Córdoba, del Lic. Pablo Martín Llanos, sobre el tema: "Enriquecimiento genérico en Argonáuticas: elementos hímnicos, trágicos y épicos en el poema de Apolonio de Rodas".I Con estas dos tesis doctorales se consolida un itinerario de investigación que, iniciado por el Dr. Buzón en aquel Simposio de 1986 y proseguido por sus discípulos y otros colegas nuestros, promete ser muy fructífero para el desarrollo de la disciplina en nuestro país, como lo demuestra el interés de los más jóvenes investigadores por la exploración de la literatura helenística.

Pasemos a la explicación del logo que contiene los vv. 22-28 del fr. 1 de los Aitia, el denominado "Prólogo contra los Telquines", con las instrucciones de Apolo Licio al poeta joven, tal vez un niño, sobre el tipo de poesía que debe cultivar. Al formato rectangular del papiro original (P. Oxy. XVII 2079), los organizadores de las Jornadas le imprimimos un formato ovoidal para dar idea de continuidad y repetición de este evento.

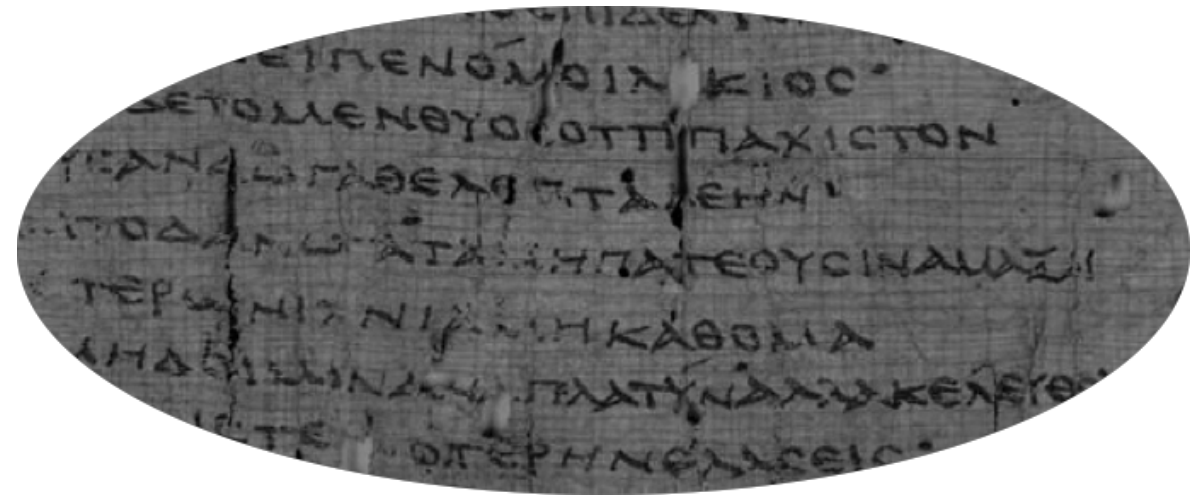


Tras la polémica contra los Telquines, sus críticos literarios, que ocupa los vv. I a 20, entendida como una discusión sobre los géneros literarios, con referencias y alusiones a la épica y a la elegía, a la tragedia y a la comedia, y con la actitud propia de un yambógrafo escribiendo en dísticos elegíacos, el poeta contrapone su propio programa poético que sigue el mandato de Apolo. Cito el pasaje en su contexto inmediato2:

Calímaco, Aetia fr. I (Pf.) 21-32:

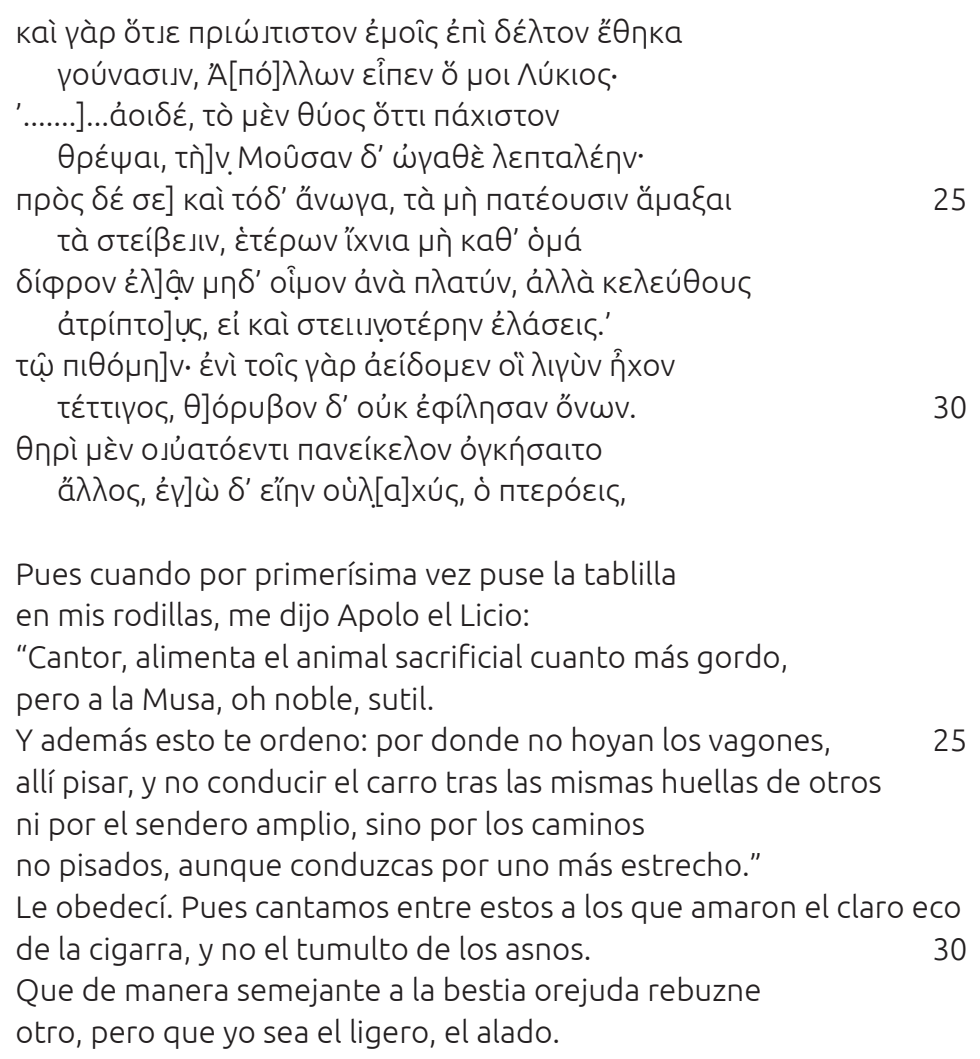

En este pasaje, el 'yo poético' contrapone a los Telquines su propio programa poético, que consiste en obedecer (v. 29: “ $\tau \tilde{\omega} \pi \mathrm{\imath} \theta$ ó $\mu \eta] v^{\prime}$ ) el mandato de Apolo Licio (v. 22), en el que el dios se dirige al poeta interpelándolo como cantor

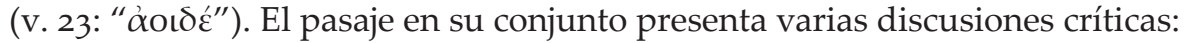
sobre la edad del poeta, sobre la identidad de Apolo Licio, sobre referencias a géneros y autores arcaicos, clásicos y contemporáneos. Remito para estas discusiones al ya citado comentario de Annette Harder (2012) y me limito aquí a señalar los términos relevantes para la comprensión del programa poético.

Comencemos por el contexto del mandato de Apolo. Con la mención de la

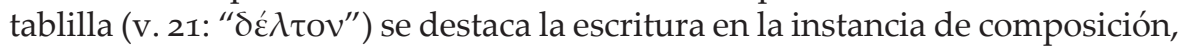

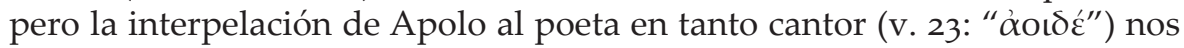
habla de una instancia performativa de su poesía. Esto se ve reforzado por la mención del canto en el v. 29 (" $\left.\alpha \varepsilon i \delta \delta \mu \mu v^{\prime \prime}\right)$ y por las referencias auditivas al eco de la cigarra y al rebuzno de los asnos (vv. 29-32), que denotan un contexto de oralidad. Nótese la estructura quiástica de estos versos: eco de la cigarra - tumulto de los asnos - rebuzne otro como la bestia orejuda - yo ligero, alado (como la cigarra). Esta estructura en quiasmo es una herencia de la tradición poética arcaica que suponía contextos de performance oral y pública, y que resulta adecuada a receptores oyentes también en el período helenístico. El
2. Texto del papiro proyectado en la exposición original, disponible en: http://163.1.169.40/cgi-bin/ library?e=q-000-00---0POxy--00-0-0-0prompt-10---4------0-11--1-en-50--20-about-2079--00031-001-0-0utfZz$8-00 \& \mathrm{a}=\mathrm{d} \& \mathrm{c}=\mathrm{PO}$ xy\&cl=search\&d $\mathrm{d}=\mathrm{H}$ ASH01cbfc45940Fd16eccd9891c 
poeta construye de este modo un contexto de performance que implica una continuidad con la praxis poética arcaica y clásica, reforzada por la continuidad de la praxis ritual del sacrificio animal en tanto ofrenda a los dioses y alimento comunitario en el banquete sacrificial.

En el mandato de Apolo, la contraposición entre la gordura del animal sacrificial

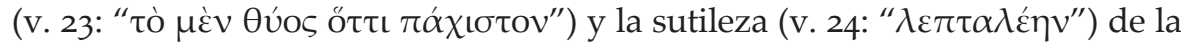
composición poética, representada por la Musa (v. 24), implica un paralelismo entre dos actividades de carácter ritual y público, comunitario, a saber, el ritual

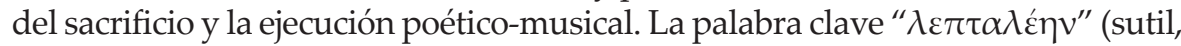
tenue, esbelta) sintetiza el programa poético de Calímaco y a esto Apolo añade

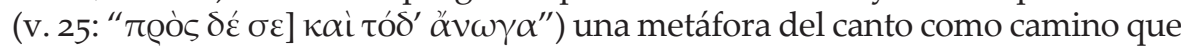
es recurrente en la tradición poética, especialmente en Píndaro y Baquílides, dos poetas a los que Calímaco en tanto filólogo se ocupó de editar y clasificar. En la metáfora del canto como camino se da una nueva contraposición, más compleja, pues se contrastan caminos y vehículos (v. 25: " $\alpha \tilde{\mu} \alpha \xi \alpha \iota$ " [vagones] /

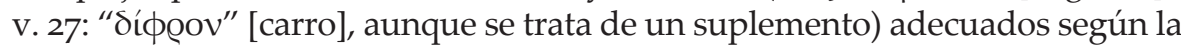
amplitud (v. 27: "oĩuov $\dot{\alpha} v \dot{\alpha} \pi \lambda \alpha \tau u ́ v$ " [por el sendero amplio]) o estrechez (v.

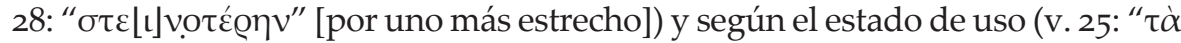

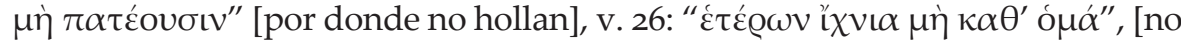
tras las mismas huellas de otros]). A estos Apolo contrapone los " $\kappa \varepsilon \lambda \varepsilon v ́ \theta$ ous /

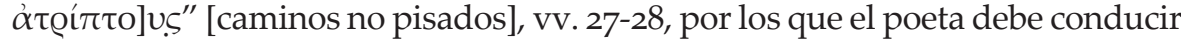

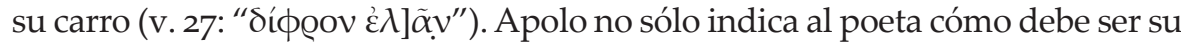

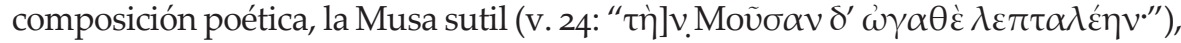
sino que también le dice lo que debe evitar, lo que implica colocar al cantor ante la tradición poética. Apolo construye al poeta como un auriga dentro de esa tradición, a la manera de Píndaro y Baquílides, reforzando de este modo el carácter performativo implicado en su interpelación inicial como cantor. En este sentido, resulta especialmente significativo un pasaje del fragmentario Peán VII b de Píndaro (fr. 52h Maehler), porque presenta un posicionamiento ante la tradición poética, en este caso explicitada como la épica, expresado con un léxico similar al utilizado por Calímaco en el mandato de Apolo:

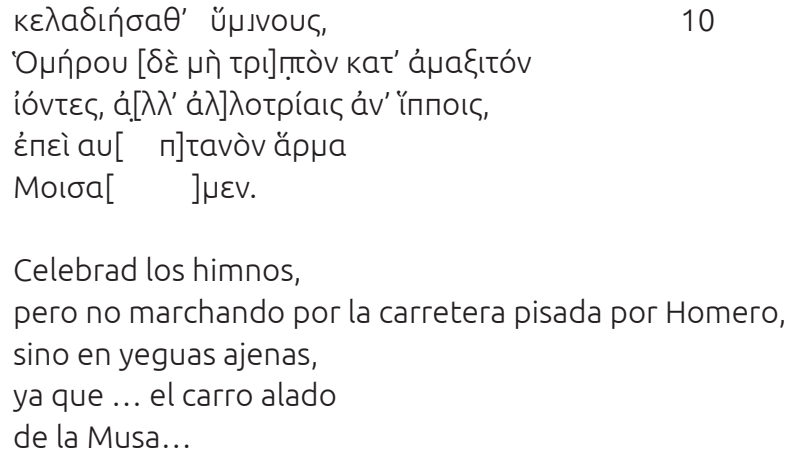

Aquí el poeta exhorta al coro, presumiblemente involucrado en la segunda persona del plural del v. 10 y en una primera del plural del v. 14, de la que solo conservamos la desinencia, a celebrar los himnos no al modo épico de Homero,

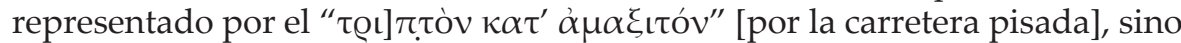
al modo lírico, representado por el " $\pi$ ] $\tau \alpha v o ̀ v ~ \alpha \varrho \varrho \mu \alpha "$ [carro alado] y por las

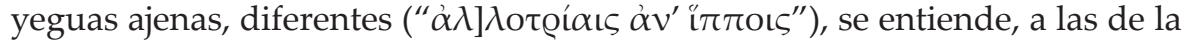
épica. Las correspondencias lexicales entre el texto del peán y el mandato de Apolo en Aitia fr. 1. 25-28 y 32 resultan evidentes: 


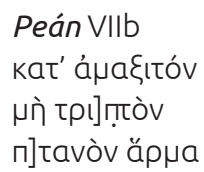

Aitia fr. 1

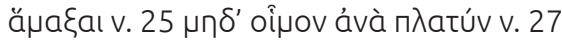

átрínto]ụs v. 29

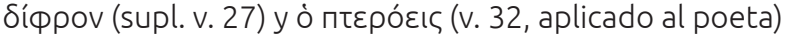

Este antecedente pindárico para el pasaje calimaqueo muestra que la innovación helenística se da dentro del marco de la tradición poética, es decir, siguiendo los códigos de los poetas líricos para apartarse del género épico. Pero como el mandato de Apolo también incluye no seguir las huellas de otros (v.

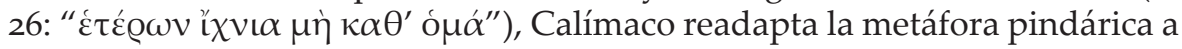
su propia exploración de la tradición poética. A la sutileza de la composición

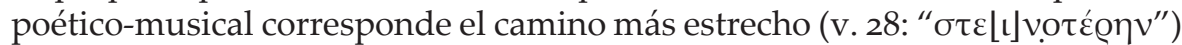
por el que el poeta-cantor-auriga deberá conducir su carro. $\mathrm{Y}$ podemos ver aquí una referencia concreta a la adopción del dístico elegíaco como metro para los Aitia, precisamente porque el pentámetro estrecha o comprime el ritmo del hexámetro. A su vez, la variedad de temáticas, de tradiciones de culto locales de las más diversas póleis del mundo helenístico, sumadas a la reelaboración de la tradición poética en su conjunto, llevan al género elegíaco arcaico y clásico a nuevas fronteras que lo amplían y enriquecen y hacen de los Aitia un modelo para el concepto de 'enriquecimiento genérico' propuesto por Abritta y Llanos en este volumen.

Para cerrar la presentación de este volume temático dedicado al estudio de la literatura helenística, y retomando la palabra clave del logo de las Jornadas,

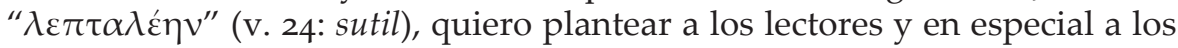
jóvenes investigadores, la siguiente reflexión: la sutileza que el poeta helenístico proclama para su composición poética es proporcional a la que se requiere del crítico moderno que interpreta a los poetas helenísticos. Ciertamente la sutileza es algo que se espera de cualquier crítico con respecto a su objeto de estudio, pero lo que los poetas helenísticos requieren de sus intérpretes es un sólido conocimiento de la literatura griega arcaica y clásica para comprender el proceso de reelaboración y resignificación de la tradición poética. A su vez, en el estado actual de las investigaciones sobre la literatura helenística, con nuevas ediciones, comentarios y numerosos estudios críticos, puede afirmarse que su exploración contribuye a la consolidación del conocimiento de la literatura precedente, y para los estudiantes de grado constituye una instancia enriquecedora para la articulación con el estudio de la literatura latina. 


\section{Q Bibliografía}

»Cameron, A. (1995). Callimachus and his Critics. Princeton: Princeton University Press.

» Fraser, P. M. (1972). Ptolemaic Alexandria. Vol. I. Text. Vol. II. Notes. Vol. III. Indexes. Oxford: Clarendon Press.

" Harder, A. (2012). Callimachus. Aetia. Introduction, Text, Translation and Commentary. Oxford: Oxford University Press.

» Pfeiffer, R. (1949). Callimachus. Vol. I. Fragmenta. Oxford: Clarendon Press.

»Pfeiffer, R. (1953) Callimachus. Vol.II. Hymni et Epigramata. Oxford: Clarendon Press.

»Prauscello, L. (2006). Singing Alexandria. Music between Practice and Textual Transmission. Leiden: Brill.

» Regtuit, R.F.; Harder, M.A.; Wakker, G.C. (1993). Callimachus. Hellenistica Groningana 1. Groningen: Peeters.

» Regtuit, R.F.; Harder, M.A.; Walkker, G.C. (2018) Drama and Performance in Hellenistic Poetry. Hellenistica Groningana 23. Groningen: Peeters.

»Stephens, S. (2003). Seeing Double. Intercultural Poetics in Ptolemaic Alexandria. Berkeley: California University Press.

» Stephens, S. (2015). Callimachus: The Hymns. Edited with Introduction, Translation and Commentary by Susan A. Stephens. Oxford: Oxford University Press.

"Vamvouri Ruffy, M. (2004). La Fabrique du divin. Les Hymnes de Callimaque à la lumière des Hymnes Homériques et des Hymnes épigraphiques, Kernos Supplements 41. Liège: Presses universitaires de Liège. 